\title{
Levels of total IgA and IgA subclasses in the serum of chronic rhinosinusitis patients
}

\author{
Hossein Aazami ${ }^{1,2}$, Farhad Seif ${ }^{1,2}$, Babak Ghalehbaghi ${ }^{3}$, Alireza Mohebbi ${ }^{3}$, Aslan Ahmadi ${ }^{3}$, \\ Pegah Babaheidarian ${ }^{4}$, Kobra Zinat Entezami ${ }^{1}$, Majid Khoshmirsafa ${ }^{1,2}$, Sahand Ghalehbaghi ${ }^{3}$, Reza Falak ${ }^{* 1,2}$
}

\section{Abstract}

Background: Different inflammatory mechanisms take part in the immunopathogenesis of chronic rhinosinusitis (CRS). Immunoglobulin (Ig) A is the first-line defense in the airway tracts and other mucosal sites, but little is reported regarding its serum level in CRS patients. The purpose of current study is to determine the serum levels of total IgA, and its subclasses (IgA1, and IgA2) in CRS with nasal polyps (CRSwNP), CRS without nasal polyps (CRSsNP), and control groups.

Methods: In this case-control study the serum levels of total IgA and IgA subclasses were determined by Nephelometry and ELISA methods, respectively. The difference of the median concentrations was analyzed with the Kruskal-Wallis test. Collected data were analyzed using SPSS and presented by GraphPad Prism software.

Results: A total of $10 \mathrm{CRSwNP}$ patient, $10 \mathrm{CRSsNP}$ patients and 10 healthy controls participated in our study. The mean age of the groups were $38.2 \pm 12.6,25.6 \pm 10.54$, and $30.1 \pm 9.5$, respectively. The concentrations of total IgA were 156(120-165), 165 (149-173), and $172(152.8-184.3) \mathrm{mg} / \mathrm{dl}$, respectively. The concentrations of IgA1 were 107 (77.9-169.9), 156.1(112.8-175.6), and 130.4 (118.8$175.2) \mathrm{mg} / \mathrm{dl}$, respectively. The concentrations of IgA2 were 26.11 (18.41-38.11), 26.96 (15.48-38.39), and 23.2 (18.42-31.78) mg/dl, respectively. There was no significant difference in total $\operatorname{IgA}(\mathrm{p}=0.120), \operatorname{IgA} 1(\mathrm{p}=0.397)$ and $\operatorname{IgA} 2(\mathrm{p}=0.925)$ serum levels among three groups.

Conclusion: Our study showed there is no difference in total IgA and IgA subclasses in the serum of CRS patients in comparison to healthy controls.

Keywords: Chronic Rhinosinusitis, Nasal polyps, CRSsNP, CRSwNP, Serum IgA, Isotype switching

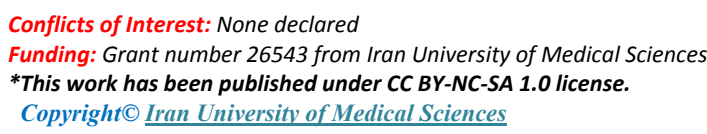

Cite this article as: Aazami1 H, Seif F, Ghalehbaghi B, Mohebbi A, Ahmadi A, Babaheidarian P, Entezami KZ, Khoshmirsafa M, Ghalehbaghi S, Falak R. Levels of total IgA and IgA subclasses in the serum of chronic rhinosinusitis patients. Med J Islam Repub Iran. 2018 (30 Sep);32:94. https://doi.org/10.14196/mjiri.32.94

\section{Introduction}

Chronic Rhinosinusitis (CRS) indicates a group of diseases characterized by permanent inflammation of paranasal sinuses. CRS is diagnosed on the basis of clinical symptoms, CT scan and endoscopic examinations (1) and is divided into two main groups depending upon the presence of nasal polyps in sinonasal tracts, including CRS with nasal polyps (CRSwNP) or CRS without nasal

Corresponding author: Dr Reza Falak, falak.r@iums.ac.ir

1. Department of Immunology, School of Medicine, Iran University of Medical Sciences, Tehran, Iran

2. Immunology Research Center, Institute of Immunology and Infectious Diseases, Iran University of Medical Sciences, Tehran, Iran

3. ENT and Head and Neck Research Center and Department, Hazrat Rasoul Akram Hospital, Iran University of Medical Sciences, Tehran, Iran

4. Pathology Department, Rasoul Akram Medical Complex, Iran University of Medical Sciences, Tehran, Iran polyps (CRSsNP) (2). Although the etiology of CRS still remains to be fully understood, usually the dominant local response in CRSsNP patients is neutrophil accumulation whereas hallmark of local response in CRSwNP is an eosinophilic pattern (3). Accumulation of inflammatory cells such as eosinophils, mast cells, neutrophils, macrophages, $\mathrm{B}$ and $\mathrm{T}$ lymphocytes, and plasma cells are

$\uparrow$ What is "already known" in this topic:

Although IgE levels increase in the sera of patients with nasal polyps, and most studies have examined its rate and role in these patients, IgA has not been studied as the most abundant antibody after IgG in sera of patients with CRS.

\section{$\rightarrow$ What this article adds:}

There is no significant difference in total $\operatorname{IgA}, \operatorname{IgA} 1$, and $\operatorname{IgA} 2$ levels in serum of patients with CRS in comparison to healthy controls. Therefore, serum IgA is not a good marker for diagnosis and prognosis of CRS, consequently local investigation of these biomarkers may result in better interpretation. 
frequently seen in CRS and is directly associated with pathological consequences of the disease (4). However, humoral immune system components, especially immunoglobulins are involved in protection against infectious diseases $(5,6)$.

Immunoglobulin (Ig) A is mainly found in mucosal tissues and fluids in secretory form and plays protective roles by neutralization of microbes and their toxic products. Plasma cells produce dimers of IgA in lamina propria, where they are transported to mucosal surfaces across epithelium barriers (7). Active translocation of IgA is carried out by polymeric immunoglobulin receptor (pIgR) and its extracellular portion, renowned as secretory component (SC) which protects IgA from proteolytic degradation. Human IgA has two subclasses named as IgA1 and IgA2 which are differently expressed in mucosal surfaces, and their expression is thought to be controlled by several cytokines such as TGF- $\beta 1$, BAFF, and APRIL (8). Although both subclasses are nearly detected in equal levels in small intestine, IgA1 is largely produced in airway tracts, and IgA2 is profoundly expressed in colon (9). Previous studies confirm that IgE level is higher in the serum of CRSwNP patients (10-12), while limited studies have focused on the role of serum IgA in CRS patients. In this regard, in the present study, we aimed to compare the serum levels of total IgA, IgA1, and IgA2 in CRSwNP and CRSsNP patients and healthy controls.

\section{Methods}

\section{Patient selection}

This case-control study was carried out in ENT and Head and Neck Research Center and Department of Hazrat Rasoul Akram hospital (IUMS, Tehran, Iran), from January 2016 to September 2017. Ten patients with CRSsNP, 10 CRSwNP patients, and 10 healthy controls who were candidates for anatomical septal deviation or rhinoplasty were recruited in the study. The diagnosis of CRSwNP and CRSsNP was performed according to EPOS criteria (European Position Paper on Rhinosinusitis and Nasal Polyps), based on clinical examination, history, nasal endoscopic and CT scan scores (1). Demographic and clinical characteristics of participants are summarized in Table 1. Healthy controls were supposed to undergo elective surgery while patients with CRS underwent surgery as a treatment protocol. Written consent was filled by all participants, and the study was approved by the Ethical Committee of Iran University of Medical
Sciences. Before blood sampling, all patients were prohibited to use oral, nasal or systemic corticosteroids or even antibiotics for at least 4 weeks before surgery. Patients who had immunodeficiencies, cystic fibrosis, bronchiectasis, chronic obstructive pulmonary disease, diabetes mellitus, neoplasia, or fungal rhinosinusitis were not included in the study.

\section{Measurement of serum total IgA, IgA1, and IgA2}

In brief, after bleeding, serum samples were aliquoted and frozen at $-80^{\circ} \mathrm{C}$. Total $\operatorname{IgA}$ was measured by Nephelometry method using Minineph ${ }^{\text {TM }}$ human IgA kit (Minineph, Birmingham, UK) according to manufacturer's instruction. IgA subclasses including IgA1 and IgA2 were assessed by indirect sandwich ELISA (MyBiosource Company, San Diego, USA) according to the kit manual. The minimum detectable amounts of the ELISA kits were 0.03 and $0.0005 \mathrm{mg} / \mathrm{dl}$, respectively.

\section{Statistical Analysis}

The differences of the median concentrations were analyzed with the Kruskal-Wallis test. Data were analyzed using SPSS version 21 and presented using Graph Pad Prism 6 software. P values less than 0.05 was considered significant.

\section{Results}

A total of 20 patients participated in our study from January 2016 to September 2017 for measuring the levels of total surum $\operatorname{IgA}$, $\operatorname{IgA} 1$, and $\operatorname{IgA} 2$, including CRSwNP and CRSsNP patients as well as healthy controls. The mean age of the participants was $38.2 \pm 12.6$ in CRSwNP patients, 25.6 \pm 10.54 in CRSsNP patients, and $30.1 \pm 9.5$ in healthy controls. There were 10 patients in CRSwNP group of whom 6 were males $(60 \%)$, and 4 were females (40\%). There were 10 in CRSsNP group of whom 7 were males $(70 \%)$, and 3 were females $(30 \%)$. There were 10 in control group of whom 5 were males $(50 \%)$, and 5 were females $(50 \%)$ (Table 1$)$.

Measurement of total IgA by Nephelometry revealed that the median levels (IQR) of total IgA were 156 (120165), 165 (149-173), and 172 (152.8-184.3) $\mathrm{mg} / \mathrm{dl}$ in CRSwNP, CRSsNP, and control groups, respectively (Fig. 1 and Table 2). There was no significant difference in the amount of total IgA among the studied groups. The concentration of IgA1 was measured by ELISA, and they were 107 (77.9-169.9), 156.1 (112.8-175.6), and 130.4

Table 1. Characteristics of control and patient groups

\begin{tabular}{lcccc}
\hline & Controls & CRSsNP & CRSwNP & P value \\
\hline Number & 10 & 10 & 10 & - \\
Age $(\mathrm{y}) \pm$ SD & $30.1 \pm 9.5$ & $25.6 \pm 10.54$ & $38.2 \pm 12.6$ & 0.019 \\
CT score & - & $7.1 \pm 5.36$ & $14.9 \pm 4.8$ & 0.003 \\
Endoscopic score & - & $0.6 \pm 0.7$ & $2 \pm 0.67$ & 0.001 \\
VAS score & - & $5.6 \pm 2.63$ & $8.4 \pm 2.5$ & 0.001 \\
\hline
\end{tabular}

Table 2. The concentrations of total IgA, IgA1, and IgA2 in the serum of studied groups

\begin{tabular}{lcccc}
\hline Group & Control & CRSsNP & CRSwNP & P value \\
\hline Serum IgA total (mg/dL) & $156(120-165)$ & $165(149-173)$ & $172(152.8-184.3)$ & 0.120 \\
Serum IgA1 (mg/dL) & $107(77.9-169.9)$ & $156.1(112.8-175.6)$ & $130.4(118.8-175.2)$ & 0.397 \\
Serum IgA2 (mg/dL) & $26.11(18.41-38.11)$ & $26.96(15.48-38.39)$ & $23.2(18.42-31.78)$ & 0.925 \\
\hline * DATA are presented as median (interquartile range) & & &
\end{tabular}




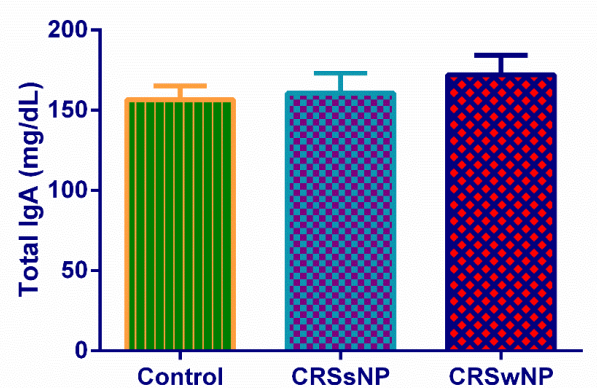

Fig. 1. The concentrations of total IgA in serum of control, CRSsNP, and CRSwNP groups.

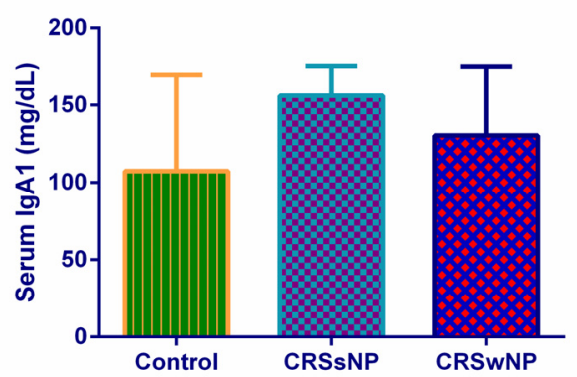

Fig. 2. The concentrations of serum IgA1 in control, CRSsNP, and CRSwNP groups.

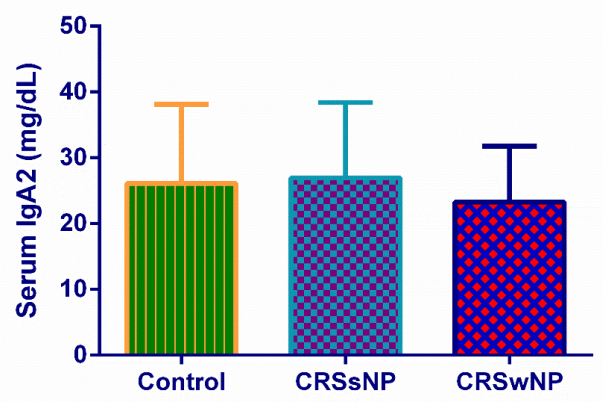

Fig. 3. The concentrations of serum IgA2 in control, CRSsNP, and CRSwNP groups.

(118.8-175.2) $\mathrm{mg} / \mathrm{dl}$ in CRSwNP, CRSsNP, and control groups sera, respectively (Fig. 2 and Table 2). There was no significant difference in the level of IgA1 in three groups. Similarly, the levels of IgA2 was also measured by ELISA, and its concentration was 26.11 (18.41-38.11), 26.96 (15.48-38.39), and $23.2(18.42-31.78) \mathrm{mg} / \mathrm{dl}$ in CRSwNP, CRSsNP, and control groups, respectively (Fig. 3 and Table 2). There was no significant statistical difference in the level of $\operatorname{IgA} 2$ in the studied groups.

\section{Discussion}

Chronic Rhinosinusitis (CRS) is an inflammatory disease affecting paranasal sinuses (1). IgA is a neutralizing antibody which is predominantly found in mucosal surfaces (7). IgA production particularly occurs within nasal polyps, and its local production is crucial for the activation of eosinophils and mast cells, which in turn influence the inflammation of local mucosal tissues (13). We investigated the levels of $\operatorname{IgA}$ and its subclasses in sera of CRS patients in comparison to healthy controls.
Results showed that there is no significant difference in the concentration of total IgA and IgA subclasses (IgA1 and IgA2) in the serum of CRSwNP and CRSsNP patients in comparison to healthy controls. Bachert et al. showed that the level of immunoglobulins, especially $\operatorname{IgA}$ is locally increased in CRSwNP patients (14). Schleimer et al. showed that local concentrations of total $\operatorname{IgA}$ were higher in nasal polyposis patients compared with CRSsNP and control groups (15) and in another study, this author and his colleagues indicated that total $\operatorname{IgA}$ levels were increased in tissue extracts from CRS patients but not in lavage fluids (10).

It has been repeatedly reported that $\operatorname{IgA}$ is elevated in tissue homogenates from patients with $\operatorname{CRSwNP}(11,16)$; however, it remains to be clarified whether these findings are as a result of increased production of $\operatorname{IgA}$ in nasal mucosa or defect in transportation to luminal parts. Mortuaire et al. investigated total IgA levels in blood and nasal secretions of allergic and non-allergic patients. They found that there is no difference between the mentioned two groups. In fact, the atopic status has no effect on the levels of $\operatorname{IgA}$ in both serum and nasal secretions (17). However, an old study reported that local IgA production occurred in both allergic and non-allergic CRSwNP patients, resulting in degranulation of cytotoxic proteins from eosinophils. In contrast to our study they counted eosinophil numbers in the nasal polyps, nevertheless they acclaimed no relationship between eosinophils and total IgA in serum and nasal secretions(18). In addition to allergic status, the microbiota composition of sinonasal tracts may play a pivotal role in either IgA production or IgA class switching. Van Zele et al. revealed that IgA, $\mathrm{IgG}$, and $\mathrm{IgE}$ concentrations against Staphylococcus aureus enterotoxins (SAEs) were significantly increased in tissue extracts, but not in the serum of nasal polyps in comparison to healthy controls (11). Therefore, it is necessary to investigate the microbiome status to find specific IgA and IgA subclasses against super antigens and other microbial agents settled down in sinonasal tracts.

Human individuals have two distinct IgA subclasses. Although both subclasses are nearly detected in equal levels in small intestine, IgA1 is largely produced in airway tracts, and $\operatorname{IgA} 2$ is profoundly expressed in the colon (9). In this regard, we aimed to measure $\operatorname{IgA} 1$ and IgA2 levels in serum of studied groups. We observed no difference in the protein concentrations of $\operatorname{IgA} 1$ and $\operatorname{IgA} 2$ in three groups. Schleimer et al. determined IgA1 and IgA2 levels in the samples taken from tissue extracts and nasal lavage by ELISA. Although IgA1 levels were significantly higher in nasal polyps, they reported only a trend toward elevated IgA2 levels. Surprisingly, neither total nor $\operatorname{IgA} 1$ or $\operatorname{IgA} 2$ levels was elevated in the lavage fluid of CRSwNP patients. These findings further focus on normal mechanisms for export of antibodies to the lumen. So that any disruptions, either Poly-Ig receptor (pIgR) dysfunction or insufficient $\mathrm{pIgR}$ expression, might occur in CRSwNP patients and lead to accumulation of antibodies within nasal tissues (10). The main limitation of our present research was small sample population. 
Therefore, it is suggested that more investigation is necessary with a larger sample size. Eventually, for future studies, we suggest to evaluate local total $\operatorname{IgA}$ and $\operatorname{IgA}$ subclasses. Furthermore, evaluation of the concentration of the cytokines involved in IgA production such as TGF$\beta$, BAFF, and APRIL is highly recommended. Furthermore, it is valuable to investigate local IgA class switching mechanism by molecular methods such as realtime PCR and the number of IgA producing B cells and plasma cells by flowcytometry and Immunohistochemistry methods. Future studies on the concentrations and the pattern of local IgA and IgA subclasses, determining the mechanisms by which IgA class switching occurs and IgA is secreted at sinonasal mucosa, as well as measurement of the ratio of $\operatorname{IgA} 1$ to $\operatorname{IgA} 2$ subclasses may develop new insights to target IgA and IgA subclasses in the treatment of CRS patients.

\section{Conclusion}

Our study showed there is no significant difference in total $\operatorname{IgA}, \operatorname{IgA} 1$, and $\operatorname{IgA} 2$ levels in serum of CRSwNP and CRSsNP patients in comparison to healthy controls. Hence, serum IgA is not a good marker for diagnosis and prognosis of CRS.

\section{Acknowledgments}

We would like to thank the personnel of ENT and Head and Neck Research Center and Department at Hazrat Rasoul Akram Hospital (IUMS, Tehran) for their kind cooperation.

Funding: This study was supported by grant number 26543 from Iran University of Medical Sciences.

\section{Conflict of Interests}

The authors declare that they have no competing interests.

\section{References}

1. Fokkens WJ, Lund VJ, Mullol J, Bachert C, Alobid I, Baroody F, et al. EPOS 2012: European position paper on rhinosinusitis and nasal polyps 2012. A summary for otorhinolaryngologists. Rhinology. 2012;50(1):1-12.

2. Bachert C, Pawankar R, Zhang L, Bunnag C, Fokkens WJ, Hamilos DL, et al. ICON: chronic rhinosinusitis. World Allergy Organ J. 2014;7(1):1

3. Van Crombruggen K, Zhang N, Gevaert P, Tomassen P, Bachert C. Pathogenesis of chronic rhinosinusitis: inflammation. J Allergy Clin Immunol. 2011;128(4):728-32.

4. Hulse KE. Immune mechanisms of chronic rhinosinusitis. Curr Allergy Asthma Rep. 2016;16(1):1.

5. Seppänen M, Suvilehto J, Lokki ML, Notkola IL, Järvinen A, Jarva H, et al. Immunoglobulins and complement factor $\mathrm{C} 4$ in adult rhinosinusitis. Clin Exp Immunol. 2006;145(2):219-27.

6. Foreman A, Boase S, Psaltis A, Wormald P-J. Role of bacterial and fungal biofilms in chronic rhinosinusitis. Curr Allergy Asthma Rep. 2012;12(2):127-35.

7. Pilette C, Godding V, Kiss R, Delos M, Verbeken E, Decaestecker C, et al. Reduced epithelial expression of secretory component in small airways correlates with airflow obstruction in chronic obstructive pulmonary disease. Am J Respir Crit Care Med. 2001;163(1):185-94.

8. Pilette C, Ouadrhiri Y, Godding V, Vaerman J-P, Sibille Y. Lung mucosal immunity: immunoglobulin-A revisited. Eur Respir J. 2001;18(3):571-88

9. Spencer J, Fraser LD. The human intestinal IgA response; burning questions. Front Immunol. 2012;3:108.

10. Hulse KE, Norton JE, Suh L, Zhong Q, Mahdavinia M, Simon P, et al. Chronic rhinosinusitis with nasal polyps is characterized by B-cell inflammation and EBV-induced protein 2 expression. J Allergy Clin Immunol. 2013;131(4):1075-83. e7.

11. Van Zele T, Gevaert P, Holtappels G, Van Cauwenberge P, Bachert C. Local immunoglobulin production in nasal polyposis is modulated by superantigens. Clin Exp Allergy. 2007;37(12):1840-7.

12. Suh KS, Park HS, Nahm DH, Kim YK, Lee YM, Park K. Role of $\operatorname{IgG}, \operatorname{IgA}$, and $\mathrm{IgE}$ antibodies in nasal polyp tissue: their relationships with eosinophilic infiltration and degranulation. J Korean Med Sci. 2002;17(3):375.

13. Pérez-Novo CA, Kowalski ML, Kuna P, Ptasinska A, Holtappels G, Van Cauwenberge P, et al. Aspirin sensitivity and IgE antibodies to Staphylococcus aureus enterotoxins in nasal polyposis: studies on the relationship. Int Arch Allergy Immunol. 2004;133(3):255-60.

14. Bachert C, Wagenmann M, Hauser U, Rudack C. IL-5 synthesis is upregulated in human nasal polyp tissue. J Allergy Clin Immunol. 1997;99(6):837-42.

15. Kato A, Peters A, Suh L, Carter R, Harris KE, Chandra R, et al. Evidence of a role for B cell-activating factor of the TNF family in the pathogenesis of chronic rhinosinusitis with nasal polyps. J Allergy Clin Immunol. 2008;121(6):1385-92. e2.

16. Tan BK, Li QZ, Suh L, Kato A, Conley DB, Chandra RK, et al. Evidence for intranasal antinuclear autoantibodies in patients with chronic rhinosinusitis with nasal polyps. J Allergy Clin Immunol. 2011;128(6):1198-206. e1.

17. Mortuaire G, Gengler I, Balden M, Capron M, Lefèvre G. Impact of allergy on phenotypic and endotypic profiles of nasal polyposis. Eur Ann Otorhinolaryngol Head Neck Dis. 2018; 135(3):159-62.

18. Tomassini M, Tsicopoulos A, Tai PC, Gruart V, Tonnel A-B, Prin L, et al. Release of granule proteins by eosinophils from allergic and nonallergic patients with eosinophilia on immunoglobulin-dependent activation. J Allergy Clin Immunol. 1991;88(3):365-75. 